\section{Patient-centred care in general dental practice: sound sense or soundbite?}

\author{
I. Mills, ${ }^{* 1}$ J. Frost, ${ }^{2}$ D. R. Moles ${ }^{3}$ and E. Kay ${ }^{4}$
}

VERIFIABLE CPD PAPER

IN BRIEF
Determine the distinguishing
characteristics of 'quality' and 'patient-
centred care' and how they relate to the
DQOF measures.
Know and understand the evidence
underpinning the measures contained
within the new contract.
Acquire support for the view that respect,
dignity, empathy, understanding, and
equality are key components of quality
care.

This paper explores the concept of patient-centred care as a dimension of quality as applied to dentistry and provides a systematic review of the literature. The new NHS dental contract, which is currently being piloted in England, is committed to delivering improvements in quality. The Dental Quality and Outcomes Framework has been developed as a tool to measure quality and focuses on three key dimensions: clinical effectiveness, safety and patient experience. A systematic review of the literature reveals a lack of information pertaining to patient-centred care within dentistry, and in particular general dental practice. It would also suggest that there is currently a poor evidence base to support the use of the current patient reported outcome measures as indicators of patient centredness.

\section{INTRODUCTION}

Patient-centred care (PCC) is a ubiquitous term used freely by healthcare professionals, healthcare managers, policy makers, politicians and patients alike. The term is also used frequently in health service literature and there are vast numbers of publications concerned with the benefits of patient-centred care, and indeed the definition of the term.

Health services research suggests that PCC leads to enhanced patient satisfaction, improved outcomes, enhanced health status and reduced use of care. ${ }^{1-4}$ It is also claims that PCC can result in greater work satisfaction for professionals and reduced levels of medical litigation. ${ }^{5}$ Such benefits are extremely desirable for patients, health professionals and commissioners and fully justify the current enthusiasm for the delivery of patientcentred care.

\footnotetext{
${ }^{1}$ NIHR Academic Clinical Fellow in General Dental Practice and Honorary Lecturer, ${ }^{3}$ Professor of Oral Health Services Research and Director of Postgraduate Education and Research, ${ }^{4}$ Foundation Dean, Peninsula Dental School and Honorary Academic Director of Dental

Public Health, Plymouth University Peninsula Schools of Medicine \&t Dentistry; ${ }^{2}$ Research Fellow (Third Gap), Institute of Health Services Research, University of Exeter Medical School

${ }^{*}$ Correspondence to: Dr lan Mills

Email: ian.mills@pds.ac.uk
}

Accepted 21 February 2013

DOI: 10.1038/sj.bdj.2013.684

${ }^{\bullet}$ British Dental Journal 2013; 215: 81-85
Patient-centredness is considered to be one of the key dimensions of quality within healthcare according to the Institute of Medicine ${ }^{6}$ (Table 1). The importance of patient-centred care has also been recognised by Lord Darzi in his review of the NHS in 2008 - High quality care for all. ${ }^{7}$ The Darzi Report defined quality in the NHS in terms of patient safety, clinical effectiveness and the experience of patients. These key factors laid the foundations for the quality indicators which were subsequently proposed in Measuring for quality improvement. ${ }^{8}$

\section{QUALITY}

Management of quality forms a central feature of recent healthcare reforms within the NHS and assessment of quality has been incorporated into primary care services contracts, including dentistry. Quality indicators are widely used within primary and secondary care medicine in the $\mathrm{UK}^{9,10}$ with patient feedback playing an increasingly important role in measuring the level of service delivered..$^{11,12}$

Providing quality care within the general dental services under the NHS has been a long held aspiration for many, but designing an effective contract to deliver this has proved a considerable challenge. In 2006 a new dental contract was introduced. It aimed to improve patient access, promote prevention, stop the 'dental treadmill' and
Table 1 Dimensions of healthcare quality (Institute of Medicine, 2001)

a) Safety

b) Effectiveness

c) Patient-centredness

d) Timeliness

e) Efficiency

f) Equitability

deliver quality. It is now generally agreed that the 2006 dental contract failed to deliver on its key objectives. ${ }^{13,14}$

These failings have been recognised ${ }^{15,16}$ and a new dental contract is now being piloted with a focus on 'quality'. The introduction of 'quality indicators' to assess performance is one feature being piloted ${ }^{17}$ and is likely to form the cornerstone of any future contract. ${ }^{18}$ The 'quality' agenda in dentistry has tended to focus on areas of access, safety and efficiency, with little regard for effectiveness, equitability or patient centredness. ${ }^{19}$ Measurement of PCC as a quality indicator will be highly relevant in this new world of performance managed dentistry, but before we can consider measuring, we must have an understanding of what it is we are trying to measure.

The Dental Quality Outcomes Framework (DQOF) is based around three dimensions of quality: clinical effectiveness, patient 
experience (centredness) and safety. 'Patient experience' would appear to have been considered an appropriate substitute for patient centredness, and there are currently seven outcome indicators within this domain. Details of the 'patient experience indicators' are shown in Table 2 .

'Patient experience' contributes 30\% of the quality 'score' in the current pilots, which equates to $3 \%$ of the overall contract value. This can be a considerable amount of money for some practices. It is therefore vitally important that domains of quality within DQOF are clearly understood, effective and valid if they are to be used to measure the quality of dental care delivered and in turn determine funding.

There has been widespread criticism of the traditional, paternalistic approach to healthcare where the doctor/dentist takes control and focuses on the condition, rather than the person. In this largely discredited model of care, the provider takes responsibility and control of the patient's healthcare. In a patient-centred approach to care, the patient retains responsibility for their own health with the support of the provider.

In medicine, terms such as 'disease-centred care' or 'doctor-centred care' are often used in a disparaging way to describe a healthcare provider who perhaps focuses on the patient's condition rather than on the patient themselves. This attitude is sometimes epitomised by the fact that physicians or surgeons refer to a patient as an organ or an injury such as 'a ruptured spleen' or 'a fractured tib' with little reference or concern for the person who is experiencing the condition. The situation is very similar in dentistry where treatments or procedures are often referred to and focused on, rather than the individual themselves. Phrases such as 'just about to do a crown prep' or 'I've got a retained root coming in this afternoon', are commonplace within dentistry. Such terminologies and attitudes do not foster a patient-centred approach and this has been further eroded by the introduction of the Unit of Dental Activity (UDA). Vacant dental positions are now advertised by the number and value of UDAs, dentists are recruited to deliver a set number of UDAs, and patients are commonly viewed and referred to in relation to UDAs. Such an approach and philosophy does not sit

\section{Table 2 Patient experience indicators}

\begin{tabular}{l|l}
\hline PE.01 & Patients reporting that they are able to speak and eat comfortably \\
\hline PE.02 & Patients satisfied with the cleanliness of the dental practice \\
\hline PE.03 & Patients satisfied with the helpfulness of practice staff \\
\hline PE.04 & Patients reporting that they felt sufficiently involved in decisions about their care \\
\hline PE.05 & Patients who would recommend the dental practice to a friend \\
\hline PE.06 & Patients reporting satisfaction with NHS dentistry received \\
\hline PE.07 & Patients satisfied with the time to get an appointment \\
\hline
\end{tabular}

Table 2 Eight dimensions of patient-centred care

\begin{tabular}{c|c|c|c}
\hline $\begin{array}{c}\text { Respect for patients' } \\
\text { values, preferences and } \\
\text { expressed needs }\end{array}$ & $\begin{array}{c}\text { Co-ordination and } \\
\text { integration of care }\end{array}$ & $\begin{array}{c}\text { Information, } \\
\text { communication } \\
\text { and education }\end{array}$ & Physical comfort \\
\hline $\begin{array}{c}\text { Emotional support } \\
\text { and alleviation of } \\
\text { fear and anxiety }\end{array}$ & $\begin{array}{c}\text { Involvement of } \\
\text { family and friends }\end{array}$ & Continuity and transition & Access to care \\
\hline
\end{tabular}

comfortably with the delivery of patientcentred care and would appear to encourage 'UDA-centred care'.

\section{WHAT IS PATIENT-CENTRED CARE?}

Despite a general consensus that PCC is desirable, it is often considered to be a vague or nebulous term which can mean different things to different people. ${ }^{20}$ Dieppe and Horne highlighted the problems in misinterpretation of the term, or use of the phrase as a soundbite, which would ultimately devalue its worth. ${ }^{21}$ This was corroborated by the work of Gillespie et al. ${ }^{22}$ who undertook 47 semi-structured interviews to gauge the opinion of various stakeholders into the 'meaning' of patient-centred care. There was considerable diversity of opinion not only between groups, but between individuals within the same stakeholder groups. In conclusion Gillespie et al. stated that 'health professionals, educationalists, managers and patient representatives have all developed different meanings of patient-centred care to reflect their own particular backgrounds and roles.'22 There is also recognition that PCC can have different interpretations dependent on the area of healthcare involved and the setting in which it is delivered ${ }^{22,23}$ and there are also fundamental differences of opinion or perspectives between groups and individuals. ${ }^{24}$

This diversity of opinion on the meaning of patient-centred care has been the major challenge in developing a definition which reflects the differing views while avoiding being either overly complex or vague and ambiguous. Much has been written on PCC, particularly within medical, nursing and health services research with a variety of definitions proposed. The number of definitions and wide interpretations of the concept give some indication of the lack of clarity which has surrounded the term since it was first introduced by Ballint in the 1960s. ${ }^{25}$

The Institute of Medicine state that 'patient-centered' means:

'providing care that is respectful of and responsive to individual preferences, needs and values, and ensuring that patient values guide all clinical decisions.'

The Picker Institute has also been highly influential in demonstrating the importance of a patient-centred approach and originally defined seven dimensions of PCC. This has since been revised and an additional dimension 'access to care' was added. The Eight Picker Principles of Patient-Centered Care can be seen in Table 3.

These dimensions of PCC were described as being relevant to in-patient care or acute services and do not necessarily translate into dentistry. This paper looks at the literature published on patient-centred care within dentistry and reflects on how the term is interpreted within this particular field of healthcare.

\section{SYSTEMATIC REVIEW OF THE LITERATURE}

A systematic review of the literature was undertaken with two key objectives: 
1. To ascertain whether an understanding of PCC had been developed in relation to dentistry

2. To assess whether there was reliable evidence available to underpin the use of this dimension of quality within the Dental Quality and Outcomes Framework.

\section{DESIGN}

As the Dental Quality Outcomes Framework (DQOF) is being piloted specifically for general dental practice in England and Wales, consideration was given to limit the literature search to dentistry delivered within primary care in England and Wales. It was felt that this would be too specific and potentially exclude some relevant publications. A decision was therefore made to include all literature related to patient-centred care and dentistry.

\section{SEARCH STRATEGY}

A systematic approach was adopted using electronic databases to search the literature, supplemented by hand searching and cross referencing. Databases searched included PubMed, MEDLINE, PsychINFO, SocINDEX, Dentistry \&t Oral Sciences Source, Cochrane and CINAHL. Search terms were based on key words and phrases such as 'patient-centred care', 'person-centred care', 'personfocused care', 'oral', 'dental' and 'dentistry'. MeSH terms were also used for 'patientcentred care' and 'dentistry'.

Additional databases were subsequently included within the search and these involved NHS Evidence, HMIC, Cochrane Oral Health and Web of Science. Further searching was conducted on the Internet via search engines such as Google and Google Scholar, and specific websites were used to search for articles or policy documents including the Kings Fund, Picker Institute, Planetree Foundation and the Institute for Patient and Family-Centered Care. These approaches were supplemented with additional search techniques including 'one generation backward searching,, 'forward citation chasing' and personal communication. These additional searches identified several papers which had not been found in the original search of the main databases.

\section{INCLUSION/EXCLUSION}

Papers which were concerned with patientcentred care and any aspect of dentistry

\begin{tabular}{|c|c|c|c|}
\hline Kulich K R et al. & $\begin{array}{l}\text { A qualitative analysis } \\
\text { of patient-centered } \\
\text { dentistry in consulta- } \\
\text { tions with dental } \\
\text { phobic patients }\end{array}$ & $\begin{array}{l}\text { J Health } \\
\text { Commun } 2003\end{array}$ & $\begin{array}{l}\text { Qualitative analysis to ascertain the key } \\
\text { features in delivering PCC to anxious } \\
\text { patients attending a specialist clinic in } \\
\text { Sweden. Model of care developed based } \\
\text { on 'holistic perception and understand- } \\
\text { ing of the patient'. }\end{array}$ \\
\hline Loignon C et al. & $\begin{array}{l}\text { Providing humanistic } \\
\text { care: dentists' experi- } \\
\text { ences in deprived areas }\end{array}$ & J Dent Res 2010 & $\begin{array}{l}\text { Qualitative research to determine what } \\
\text { features of PCC are most effective in } \\
\text { delivering dental care to people in pov- } \\
\text { erty. Data collected from semi-structured } \\
\text { interviews with eight dentists in Canada } \\
\text { who have experience of treating this } \\
\text { patient group. Key themes based around } \\
\text { socio-humanistic approach recognised. }\end{array}$ \\
\hline McNair A et al. & $\begin{array}{l}\text { A qualitative study } \\
\text { to develop a tool to } \\
\text { examine patients' } \\
\text { perceptions of NHS } \\
\text { orthodontic treatment }\end{array}$ & J Orthod 2006 & $\begin{array}{l}\text { Qualitative research to determine aspects } \\
\text { of orthodontic treatment considered } \\
\text { important for adolescents undergoing } \\
\text { orthodontic treatment. Data collected } \\
\text { by conducting focus groups of patients. } \\
\text { Analysis highlighted the importance of } \\
\text { PCC and described key features. }\end{array}$ \\
\hline Scambler S et al. & $\begin{array}{l}\text { Professional attitudes } \\
\text { towards disability in } \\
\text { special care dentistry }\end{array}$ & JDOH 2011 & $\begin{array}{l}\text { Qualitative research to explore attitudes } \\
\text { of staff working in special care den- } \\
\text { tistry towards disability and provi- } \\
\text { sion of dental care. Data collected by } \\
\text { semi-structured interviews with staff. } \\
\text { Analysis highlighted importance of PCC } \\
\text { and revealed key features. }\end{array}$ \\
\hline
\end{tabular}

were included. All forms of publication or article were included irrespective of the nature of the study, the setting or the demographics, as long as it was published in English. Articles which were not concerned with dentistry were excluded at this stage.

\section{SEARCH OUTCOME}

The total number of publications meeting the inclusion criteria was 85 papers. Following initial screening the full text of 49 papers were obtained and assessed. Assessment of each article against the screening criteria was undertaken by the first author (IJM) with the advice and support of the rest of the research team. The full text of the 49 papers included within the literature review was analysed in detail and a data extraction tool used to assess relevance to the subject matter. At this stage a further 18 papers were excluded as they were not considered specific to the study. The remaining 31 papers were categorised on the basis of their relevance to patient-centred care and the evidence based approach within the paper.

\section{FINDINGS}

Our primary objectives were to ascertain what features of patient-centred care were considered relevant to dentistry and whether this was based on opinion or evidence-based research. Only four papers $^{26-29}$ fulfilled the inclusion criteria and provided an evidence-based approach to describing the key features of patientcentred care within dentistry. The key papers are shown in Table 4 with a brief summary of the nature of the study conducted. From our literature review, there would appear to have been no published studies on patient-centred care within general dental practice.

A significant proportion of papers identified in the initial search were opinion pieces $(60 \%)$ and although they could not be considered to be 'evidence based', they may still provide insight and value to an understanding of PCC in dentistry. Many of the opinion papers describe the features identified in the four papers above, ${ }^{26-29}$ but in addition they also mention the importance of oral health promotion, ${ }^{30,31}$ self care, ${ }^{31}$ empowerment, ${ }^{30,32,33}$ physical comfort ${ }^{34}$ and shared decision making. ${ }^{30,32,33}$ Such features are represented in much of the medical and nursing literature but are not highlighted in the four key papers listed in Table 4 which relate to PCC in dentistry

\section{DISCUSSION}

The four key papers which have attempted to understand the concept of PCC have done so within specific areas of dentistry 
which although related may have distinct differences. Three of the studies (Kulich, Loignon and Scambler) focus on vulnerable patients, while the paper by McNair et al. is concerned with adolescents undergoing orthodontic treatment. None of the papers were conducted within a general dental practice setting and the groups studied were not representative of the patients regularly attending the majority of high street practices.

It is interesting to note that three of the papers, (Kulich, Loignon and Scambler) relied on healthcare workers' interpretation of PCC rather than engaging with patients or carers themselves. The wealth of knowledge and experience within the healthcare professions needs to be recognised, but ultimately it is patients' views which need to be considered and adequately represented when we wish to understand 'patient-centred care'. This could be considered as a key failing of the current evidence base and one which needs to be addressed in future research.

It can be concluded from this work that the term 'patient-centred care' is widely used but poorly understood. This is highlighted by the fact that a large number of the papers screened were excluded as they did not meet the inclusion criteria. This was predominately due to the fact that the term 'patient-centred' was being used purely as a descriptive term with little consideration given to its meaning, or the context in which it was being used. This can create confusion within healthcare professionals, where individuals may have vastly different values, expectations and perceptions of what is successful patient centred care. ${ }^{35}$ This is illustrated by the range of features and characteristics described within the dental literature and the lack of evidence based research on PCC.

Despite this lack of congruity, the recurring themes within the literature seem to highlight the importance of a humanistic approach. Respect, dignity, empathy, understanding, 'listened to' and equality are all terms which would appear to be valued by patients. Sadly, this level of import does not appear to be adequately reflected in the development of suitable quality indicators currently being piloted in the Dental Quality Outcomes Framework.
The DQOF predominately focuses on patient satisfaction rather than aspects of patient-centred care. Patient satisfaction is not considered a reliable marker of 'quality', nor does it necessarily result in improved health outcomes. ${ }^{36}$ In view of this, the "patient experience" domain would appear to be a poor indicator of quality.

\section{CONCLUSION}

There has been an increasing focus on the delivery of quality within healthcare and a growing realisation that patient reported outcome measures are key. In June 2010 the Secretary of State for Health, Rt. Hon. Andrew Lansley MP made his inaugural speech as a Government Minister entitled, My ambition for patient-centred care. ${ }^{36} \mathrm{He}$ stated quite clearly that patients should be at the centre of the NHS and the focus of everything we do as a healthcare professional. '...patients must be at the heart of everything we do, not just as beneficiaries of care, but as participants, in shared decision-making. As patients, there should be no decision about us, without us. ${ }^{36}$

This has been dramatically reinforced by the publication of the Francis Report ${ }^{37}$ into events at Mid-Staffordshire Healthcare Trust. The widespread failings documented within the report highlight a lack of patient-centred care and it is interesting to note that the first recommendation is headed 'Putting the patient first':

'The patients must be the first priority in all of what the NHS does.'

The report details the 'lack of compassion and an uncaring attitude' among some of the staff at the Hospital Trust which is the antithesis of patient-centred care. Although the inquiry predominately focuses on secondary care, the impact of this report, and the subsequent recommendations, are likely to have widespread ramifications throughout the NHS, including dentistry. Robert Francis ${ }^{37}$ is profoundly critical of the 'high priority placed on achievement of targets' which will be all too familiar to dentists working within the current NHS contract.

Delivery of patient-centred care is an important aspect of providing quality dentistry, but regrettably it would appear to have been supplanted by performance indicators and surrogate markers. Performance management is a necessity to ensure the NHS delivers value for money. However, we need to be quite clear as to the distinct difference between performance indicators and quality indicators. The terms are not interchangeable and are certainly not synonymous. If the future dental contract is to deliver improvements in quality, we must focus on quality and use appropriate indicators to measure this effectively. Patients should be the focus of everything we do within the NHS, and as clinicians we need to understand that "patient reported outcome measures' (PROMs) are every bit as relevant as clinical outcome measures.

The Department of Health reinforced their commitment to delivering quality through publication of Securing excellence in commissioning NHS dental services. ${ }^{38}$ Dental services will no longer be commissioned locally, but will instead be the responsibility of the National Health Service Commissioning Board (NHSCB). The NHSCB state unequivocally that their vision for the future is for:

'an NHS that promotes health and wellbeing; which provides care that is centred on patients, is evidenced, informed and innovative, to achieve high quality, best outcomes for patients and value for money. ${ }^{38}$

It is important that we understand the term 'patient-centred care' in relation to general dental practice and attempt to define what it actually means to commissioners and providers of primary care dentistry, but more importantly the patients who are the recipients of that care. An understanding of the term, "patient-centred care', is the first step in ensuring delivery to an agreed standard as part of routine care within general dentistry in the NHS.

The present literature review demonstrates the current lack of understanding of supposedly patient-centred quality measures within dentistry and highlights the dearth of evidence-based literature supporting the measures contained within the new dental contract. This lack of evidence needs to be addressed if we wish to measure quality effectively and ultimately deliver high quality, patient-centred care for our patients rather than our current preoccupation with target driven, 'UDAcentred care'.

\section{FINAL CONCLUSIONS}

- Patient centredness is widely recognised as a fundamental measure 
of quality in healthcare

- The current Dental Quality Outcome Framework does not appear to measure patient-centred care but focuses on patient satisfaction which is not a dimension of quality

- There is presently inadequate evidence available to understand PCC within general dentistry, let alone measure it

- Further research is necessary to understand the key features of PCC within general dental practice within the NHS

- A tool to measure PCC needs to be developed to support effective assessment of quality within the new dental contract

- Future research should incorporate patients' views in order to determine a true understanding of the key features of PCC within dentistry.

1. Stewart M, Brown J B, Donner A et al. The impact of patient-centered care on outcomes. J Fam Pract 2000; 49: 796-804.

2. Epstein R M, Mauksch L, Carroll J, Jaén C R. Have you really addressed your patient's concerns? Fam Pract Manag 2008; 15: 35-40.

3. Bertakis K D, Azari R. Patient-centered care is associated with decreased health care utilization. J Am Board Fam Med 2011; 24: 229-239.

4. Bertakis K D, Azari R. Determinants and outcomes of patient-centered care. Patient Educ Couns 2011 85: 46-52.

5. Irwin R S, Richardson N D. Patient-focused care: using the right tools. Chest 2006; 130(1 Suppl): 73S-82S.

6. Institute of Medicine. Crossing the quality chasm: a new health system for the 21st century. Washington, DC: National Academy Press, 2001.

7. Darzi A. High quality care for all. NHS Next Stage
Review Final Report. London, 2008.

8. Information Centre. High Quality Care for All. Measuring for Quality Improvement: In: Department of Health, editor. London: The Stationary Office; 2009.

9. Checkland K, Harrison S. The impact of the Quality and Outcomes Framework on practice organisation and service delivery: summary of evidence from two qualitative studies. Qual Prim Care 2010; 18: $139-146$.

10. Steel N, Willems S. Research learning from the UK Quality and Outcomes Framework: a review of existing research. Qual Prim Care 2010; 18: 117-125.

11. Greenhalgh J. The applications of PROs in clinical practice: what are they, do they work, and why? Qual Life Res 2009; 18: 115-123.

12. Palfreyman S. Patient-reported outcome measures and how they are used. Nurs Older People 2011; 23: 31-36.

13. Milsom K M, Threlfall A, Pine $K$, Tickle M, Blinkhorn A S, Kearney-Mitchell P. The introduction of the new dental contract in England - a baseline qualitative assessment. Br Dent J 2008; 204: 59-62.

14. Chestnutt I G, Davies L, Thomas D R. Practitioners' perspectives and experiences of the new National Health Service dental contract. Br Dent J 2009; 206: E18.

15. Committee THoCHS. Report on dental services. Fifth Report of Session 2007-2008. London: The Stationery Office, 2008

16. Davies B J B, Macfarlane F. Clinical decision making by dentists working in the NHS General Dental Services since April 2006. Br Dent J 2010; 209: E17.

17. Department of Health. Dental Quality and Outcomes Framework. The Stationery Office, 2011.

18. Department of Health. NHS Dental Contract: proposals for pilots. London: The Stationery Office, 2010

19. Mills I, Batchelor P. Quality indicators: the rationale behind their use in NHS dentistry. Br Dent J 2011 211: 11-15.

20. International Alliance of Patients' Organizations 2011. www.patientsorganizations.org

21. Dieppe $P$, Horne R. Soundbites and patient centred care $B M J$ 2002 : 325: 605.

22. Gillespie R, Florin D, Gillam S. How is patientcentred care understood by the clinical, managerial and lay stakeholders responsible for promoting this agenda? Health Expect 2004; 7: 142-148.

23. Mead N, Bower P. Patient-centred consultations and outcomes in primary care: a review of the literature. Patient Educ Couns 2002 : 48: 51-61.

24. Robinson J H, Callister $L C$, Berry J A, Dearing $K A$ Patient-centered care and adherence: definitions and applications to improve outcomes. J Am Acad
Nurse Pract 2008; 20: 600-607.

25. Balint $M$. The doctor, his patient, and the illness. Lancet 1955; 268: 683-688.

26. Kulich K R, Berggren U, Hallberg L R M. A qualitative analysis of patient-centered dentistry in consultations with dental phobic patients. J Health Commun 2003; 8: 171-187.

27. Loignon C, Allison P, Landry A, Richard L, Brodeur $J$ M, Bedos C. Providing humanistic care: dentists experiences in deprived areas. J Dent Res 2010; 89: 991-995.

28. McNair A, Gardiner P, Sandy J R, Williams A C. A qualitative study to develop a tool to examine patients' perceptions of NHS orthodontic treatment. J Orthod 2006; 33: 97-106.

29. Scambler S, Low E, Zoitopoulos L, Gallagher J E. Professional attitudes towards disability in special care dentistry. J Disabil Oral Health 2011: 12: 51-58.

30. Kalkwarf K L. Patient-centered care and today's dental practice. J Am Coll Dent 1997; 64: 6-8.

31. Bauer J, Spackman S, Chiappelli F, Prolo P. Interdisciplinary resources optimize Evidence-Based Dental Practice. J Evid Based Dent Pract 2005; 5: 67-73.

32. Phillips C. Patient-centered outcomes in surgical and orthodontic treatment. Semin Orthod 1999; 5: 223-330.

33. Roskell C, White D, Bonner C, Fairchild R. [Commentary on] Developing patient-centred care in health professionals: reflections on introducing service-learning into the curriculum. Int J Ther Rehabil 2012: 19: 448-457.

34. Brennan M, Houston $F$, O'Sullivan $M$, O'Connell B. Patient satisfaction and oral health-related quality of life outcomes of implant overdentures and fixed complete dentures. Int J Oral Maxillofac Implants 2010; 25: 791-800

35. Little $P$, Everitt $H$, Williamson I et al. Preferences of patients for patient centred approach to consultation in primary care: observational study. BMJ 2001; 322: 468-472.

36. Kupfer JM, Bond EU. Patient satisfaction and patient-centered care: necessary but not equal. JAMA 2012; 308(2): 139-40.

37. Andrew Lansley. Secretary of State for Health's speech - 'My ambition for patient-centred care', Department of Health; 28th June 2010.

38. Francis Report. Independent Inquiry into care provided by Mid Staffordshire NHS Foundation Trust January 2005 - March 2009. London: HMSO2013.

39. NHS Commissioning Board. Securing excellence in commissioning NHS dental services. In: Department of Health, editor. London: HMSO; 2013. 